\title{
HPLC Quantification of Dexamethasone Palmitate in Bronchoalveolar Lavage Fluid of Rat after Lung Delivery with Large Porous Particles
}

\author{
Alain N'Guessan 1,2*, Armand Koffi'2, Ismaël L. Dally², Christophe N'Cho Amin², Claire Gueutin', \\ Nicolas Tsapis ${ }^{1}$, Elias Fattal ${ }^{1}$ \\ ${ }^{1}$ Institute Galien Paris-Sud, Paris-Sud University, Orsay, France \\ ${ }^{2}$ School of Pharmacy, University Félix Houphouet-Boigny, Abidjan, Côte d'Ivoire \\ Email: ^dr.ngues@gmail.com, ${ }^{\star}$ al.ngues@gmail.com
}

How to cite this paper: N'Guessan, A., Koffi, A., Dally, I.L., Amin, C.N.C., Gueutin, C., Tsapis, N. and Fattal, E. (2019) HPLC Quantification of Dexamethasone Palmitate in Bronchoalveolar Lavage Fluid of Rat after Lung Delivery with Large Porous Particles. American Journal of Analytical Chemistry, 10, 404-414.

https://doi.org/10.4236/ajac.2019.109028

Received: December 28, 2016

Accepted: September 16, 2019

Published: September 19, 2019

Copyright $\odot 2019$ by author(s) and Scientific Research Publishing Inc. This work is licensed under the Creative Commons Attribution International License (CC BY 4.0).

http://creativecommons.org/licenses/by/4.0/

\section{(c) (i) Open Access}

\begin{abstract}
A high-performance liquid chromatography (HPLC) method has been developed and validated for the determination of dexamethasone palmitate (DXP) in bronchoalveolar fluid lavage samples (BALF). DXP in rat BALFs containing the internal standard (IS), testosterone decanoate (TD), was extracted using a mixture of chloroform and methanol $(9: 1, \mathrm{v} / \mathrm{v})$. Extracts were then centrifuged, dried and dissolved in acetonitrile. A chromatographic separation based on an isocratic elution was done using acetonitrile and water $(85: 15, \mathrm{v} / \mathrm{v})$ as a mobile phase at a flow rate of $1.2 \mathrm{~mL} / \mathrm{min}$. The graph of the developed method was linear within the tested calibration range of $0.5-40$ $\mu \mathrm{g} / \mathrm{mL}$. The overall extraction recovery of DXP from BALF samples was $84.3 \% \pm 1.6 \%$. The accuracy (relative error) and precision (coefficient of variation) values were within the pre-defined limits of $\leq 15 \%$ at all concentrations. This methodology has been applied to determine levels of DXP in BALF samples collected from rats treated with DXP large porous particles. The measured concentrations were successfully evaluated using a non-compartment pharmacokinetic model. Since the developed method requires only a microvolume $(100 \mu \mathrm{L})$ of BALF sample for analysis, it is therefore particularly suitable for the evaluation of drug biodistribution in lung.
\end{abstract}

\section{Keywords}

Dexamethasone Palmitate, Bronchoalveolar Lavage Fluid, HPLC

\section{Introduction}

Glucocorticoids are the most effective therapy available for patients with asthma 
[1] [2]. Glucocorticoids could be administered either orally, parenteral route or much more safely, by inhalation [3]. Inhaled glucocorticoids may have direct inhibitory effects on many of the cells involved in airway inflammation in asthma, including macrophages, T-lymphocytes, eosinophils, and airway epithelial cells. Inhalation allowed to have high local concentrations of glucocorticoids in the airway mucosa which limit the increase of steroid concentrations in the rest of the body [4] [5]. In previous work, we have formulated large porous particles containing dexamethasone palmitate intended to be administered by the pulmonary route for a prolonged action [6] [7]. Indeed, dexamethasone palmitate is a lipophilic molecule which allows high distribution to inflammatory lesions, high uptake by macrophages [8] [9]. Although inhaled formulations of dexamethasone palmitate have been extensively studied, little is known about the lung distribution of dexamethasone palmitate and its rate of conversion to dexamethasone after administration. However, for dexamethasone palmitate, only one assay method in lung fluid was reported in the literature. Indeed, Wijagkanalan et al. (2008) described a method for in vitro assay of DXP by HPLC using the hydroxyprogesterone caproate as internal standard [10]. The concentration of DXP in lung tissue was determined using Proteostain Protein Quantification Kit (Dojindo, Kumamoto, Japan) without any description [10] [11]. The objective of this work is therefore to develop a simple and sensitive method for the determination of dexamethasone palmitate in a bronchoalveolar fluid lavage (BALF) and its application to a pulmonary biodistribution study.

\section{Materials and Methods}

\subsection{Chemicals and Reagents}

Dexamethasone palmitate (DXP, 99\%) was provided by Interchain (France), Testosterone decanoate (TD, 98\%) for use as internal standard (IS) (Figure 1), was provided by Sigma-Aldrich (France), 1,2-dipalmitoyl-sn-glycero-3-phosphatidylcholine (DPPC, 99\%) by Corden Pharma (Switzerland) and hyaluronic acid, sodium salt 95\% (HA) (MW = $1000 \mathrm{kDa}$ ) by Acros Organics. HPLC-grade methanol and acetonitrile were purchased from Carlo Erba (Italy). All chemicals used, were of analytical grade. Water was purified using a RIOS/MilliQ system from Millipore (France).

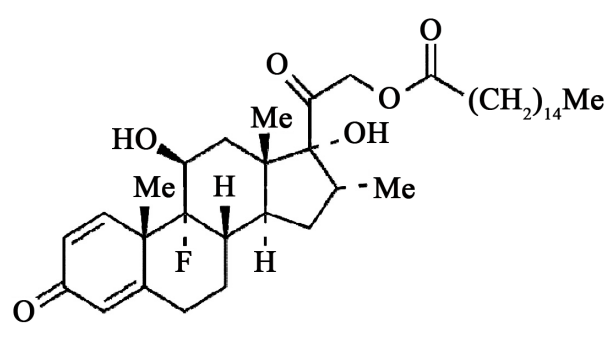

(a)

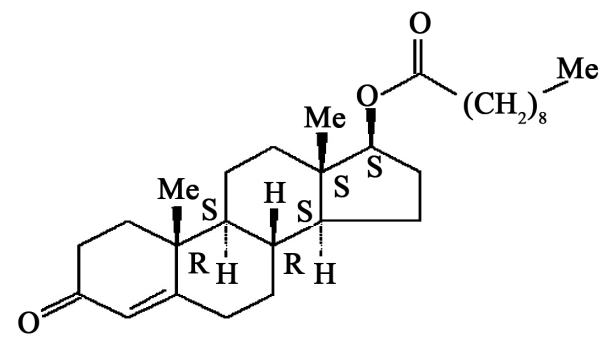

(b)

Figure 1. Chemical structures of dexamethasone palmitate (a) and testosterone decanoate (b). 


\subsection{Porous Particles Preparation}

An aqueous solution of HA was prepared dissolving $200 \mathrm{mg}$ of HA into $150 \mathrm{ml}$ of water upon magnetic stirring at room temperature. An ethanolic solution was prepared by dissolving $750 \mathrm{mg}$ of DPPC and $50 \mathrm{mg}$ of DXP into $350 \mathrm{ml}$ of ethanol absolute. Ethanolic and aqueous solutions were then mixed at a ratio of $70 / 30(\mathrm{v} / \mathrm{v})$ prior to spray-drying and the mixture maintained under moderate stirring while fed into the spray-dryer. Spray drying was performed using a mini spray-dryer BÜCHI B-290 (France) equipped with a $0.7 \mathrm{~mm}$ diameter two-fluid nozzle, which operates in a co-current mode according to conditions detailed in Table 1 [12].

\subsection{Animals}

Sprague Dawley male rats with average weight of $300 \mathrm{~g}$ were obtained from Harlan Laboratory (Gannat, France). All animal experiments were carried out in accordance with the Principles of Laboratory Animal Care as adopted and propagated by the EU guidelines for Animal Experiments (86/609/EEC and 2010/63/EU) and Legislation in force in France (Decree No. 2013-118 of February 1,2013$)$ [13]. They were housed 4 per cage while on study in accordance to EEC guidelines. The light/dark cycle was $12 \mathrm{~h} / 12 \mathrm{~h}$. The temperature in the animal room was ambient room temperature of approximately $25^{\circ} \mathrm{C}$ and the ambient humidity was in the range of approximately $35 \%-60 \%$. Animals were allowed access to food and water ad libitum throughout the duration of the study [14].

\subsection{Bronchoalveolar Administration}

Rats were anesthetized with an intraperitoneal injection of a mixture of ketamine $\left(100 \mathrm{mg} \cdot \mathrm{kg}^{-1}\right)$ and xylazine $\left(10 \mathrm{mg} \cdot \mathrm{kg}^{-1}\right)$ and then intratracheally administered with $3 \mathrm{mg}$ of DXP powder corresponding to $150 \mu \mathrm{g}$ of DXP using a Microsprayer (Penn Century, Philadelphia, PA) [15] [16]. Powder was delivered through the insufflation device by rapidly pushing a $2 \mathrm{~cm}^{3}$ bolus of air through

Table 1. Spray drying conditions used to obtain the DXP porous particles.

\begin{tabular}{cc} 
Parameters & Operational conditions \\
\hline Feed flow rate $(\mathrm{mL} / \mathrm{min})$ & 17 \\
Inlet temperature $\left({ }^{\circ} \mathrm{C}\right)$ & $150 \pm 2$ \\
Outlet temperature $\left({ }^{\circ} \mathrm{C}\right)$ & $55 \pm 4$ \\
Aspiration setting $(\%)$ & 100 \\
Air-flow rate $(\mathrm{L} / \mathrm{h})$ & 414 \\
\hline
\end{tabular}


the device. After administration, rats were supported vertically for $1 \mathrm{~min}$. Bronchoalveolar fluid was collected at $\mathrm{t}=30 \mathrm{~min}, 1 \mathrm{~h}, 2 \mathrm{~h}, 3 \mathrm{~h}, 4 \mathrm{~h}, 6 \mathrm{~h}, 18 \mathrm{~h}$ and $24 \mathrm{~h}$ after administration. At least 3 different rats were used for each time point. Bronchoalveolar lavage fluid (BALF) was collected by lavaging lungs three times with $1 \mathrm{~mL}$ of PBS per intratracheal lavage [17] [18]. The lungs were massaged and the fluid withdrawn immediately and collected in centrifuge tube. The rats were euthanized by cardiac puncture under deep isoflurane anesthesia before BALF collection. The trachea was cannulated using an 18-gauge needle adaptor for subsequent injection and retrieval of BALF. Then BALF collected containing the lung cells was frozen at $-80^{\circ} \mathrm{C}$ until further analysis [19].

\subsection{Preparation of Calibration Standards and Quality Control Samples}

Acetonitrile stock solutions of DXP $(100 \mu \mathrm{g} / \mathrm{mL})$ and TD $(10 \mu \mathrm{g} / \mathrm{mL})$ were prepared and stored at $\left(-20^{\circ} \mathrm{C}\right)$ until use. The DXP stock solution was diluted with acetonitrile to give a series of standard solutions with concentrations ranging from $1 \mu \mathrm{g} / \mathrm{mL}$ to $80 \mu \mathrm{g} / \mathrm{mL}$. The calibration samples were prepared by diluting 1 volume of each standard solution with 1 volume of BALF. The final concentrations of calibration samples used to draw the calibration-curve ranged from 0.5 to $40 \mu \mathrm{g} / \mathrm{mL}(0.5,2,5,10,20$ and $40 \mu \mathrm{g} / \mathrm{mL})$. Standards for calibration were stored at $-20^{\circ} \mathrm{C}$ until the use [20] [21].

\subsection{Sample Preparation}

Extraction method of DXP in BALF was performed by using a mixture chloroform: methanol (9:1 v:v) [22] [23]. In an amber glass tube, $100 \mu \mathrm{L}$ of BALF, 100 $\mu \mathrm{L}$ of different concentrations of standard solutions of DXP $(0.5-40 \mu \mathrm{g} / \mathrm{mL})$ and $100 \mu \mathrm{L}$ of IS $(2.64 \mu \mathrm{g} / \mathrm{mL})$ were mixed with a vortex during $30 \mathrm{~s}$. Then $3 \mathrm{~mL}$ of a mixture chloroform: methanol (9:1, v:v) were added in the tube. Sample was vortexed for $3 \mathrm{~min}$ to obtain protein precipitation then was centrifuged for 10 min at 10,000 rpm using a centrifuge (Jouan GR 412, France). The organic phase in the bottom was transferred into a clean amber vial and evaporated to dryness under a stream of nitrogen at $30^{\circ} \mathrm{C}$. The residue was then reconstituted into 100 $\mu \mathrm{L}$ of acetonitrile and vortexed prior to analysis using HPLC conditions described below [24] [25].

\subsection{HPLC Method}

Determination of DXP concentration in BALF was performed by HPLC. A Water 2707 autosampler chromatographic system was employed equipped with a Waters $^{\mathrm{TM}} 1525$ binary HPLC pump, a Waters ${ }^{\mathrm{TM}} 2998$ photodiode array detector, and a Waters ${ }^{\mathrm{TM}}$ Breeze software. The analysis was performed at $240 \mathrm{~nm}$ using a Symmetry Shield ${ }^{\mathrm{TM}} \mathrm{RP} 18$ column $(5 \mu \mathrm{m}, 250 \times 4.6 \mathrm{~mm}$; Waters, France). Column temperature was maintained at $40^{\circ} \mathrm{C}$ using a column Heater (Model 1500, Waters Corporation). The mobile phase consisted in a mixture of water: acetonitrile (15:85 (v: v)) and was pumped in isocratic mode for 40 min through the column with a 
flow rate of $1.2 \mathrm{~mL} / \mathrm{min}$. The sample volume injected was of $50 \mu \mathrm{L}$ [26] [27].

\subsection{Validation}

The method was validated according to the criteria developed by the International Conference of Harmonization (ICH) [28]. The parameters evaluated to assess the reliability of the results consist of the linearity of the chromatographic response as a function of analyte concentration from 0.5 to $40 \mathrm{mg} / \mathrm{mL}$, the repeatability of the chromatographic analysis of the reference solution at three (3) levels of concentration: 2,10 and $40 \mathrm{mg} / \mathrm{mL}(\mathrm{n}=6)$, the repeatability of chromatographic analysis of a sample of BALF $(\mathrm{n}=6)$, the repeatability of the procedure $(n=6)$. The limits of detection (signal-to-noise ratio of 3$)$ and quantification (signal-to-noise ratio of 10) determined were assessed from serial dilutions of the standard solution of DXP [29] [30].

\subsection{Statistical Treatment}

The linearity of the response of DXP was assessed from a scatter plot. The regression line was determined according to the least squares method. An analysis of variance (ANOVA) was performed to test the statistical significance and the overall slope of the regression line. The accuracy was assessed through the coefficient of variation calculated from the ratio of the standard deviation of the mean of each series of measurements. The level of statistical significance was set at 0.05 [31] [32].

\subsection{Application}

The validated method was applied to a series of DXP in BALF samples collected from rats treated with DXP large porous powder and the measured concentrations were fitted using a non-compartment pharmacokinetic model [33] [34].

\section{Results and Discussions}

\subsection{Method Optimisation}

\subsubsection{Selection of Solvents and Separation Conditions}

Different dilutions of the mixture acetonitrile:water (40:60, 50:50, 75:25, 85:15, 100: $0, \mathrm{v} / \mathrm{v})$ at different temperatures $\left(20^{\circ} \mathrm{C}, 30^{\circ} \mathrm{C}\right.$ and $\left.40^{\circ} \mathrm{C}\right)$ were tested. Better peak shapes were obtained with acetonitrile:water $(85: 15, \mathrm{v} / \mathrm{v})$ at $40^{\circ} \mathrm{C}$. Using a short column $(5 \mu \mathrm{m}, 250 \times 4.6 \mathrm{~mm})$ to achieve the separation in the shortest time possible resulted in an optimal separation. Under these conditions, a minimum of 50 separations can be achieved with the same set of separation vials without noticeable drift of migration times due to elution solvents.

\subsubsection{Selection of Internal Standard}

The use of an IS seems useful to take into account the rate of DXP extraction by the extraction method used. Potential candidates of IS were tested for their structural similarity with DXP as testosterone decanoate, hydroxyprogesterone caproate and dexamethasone acetate. Testosterone decanoate was selected as it 
gives a similar profil of extraction with DXP and a retention time $(\mathrm{mn})$ near that of DXP peak.

\subsubsection{Selection of Detection Wavelength}

A screening of DXP and IS standard sample was carried out and the maximum absorption wavelength of DXP and IS peaks was at $240 \mathrm{~nm}$.

\subsection{Validation}

Chromatographic conditions used provided sufficient resolution with elution of DXP and IS respectively at $27.1 \mathrm{~min}$ and $23.9 \mathrm{~min}$ (Figure 2). There were no significant ( $\geq 10 \%$ of LLQ area) interferences at either of these retention times and the selectivity of the method is demonstrated by the representative HPLC chromatograms presented in Figure 2 [27]. A linearity range has been set to the concentration range of 0.5 to $40 \mu \mathrm{g} / \mathrm{mL}$ of DXP with a coefficient of determination $\mathrm{R}^{2}=0.999$. The line of regression equation was established: $Y=(0.262 \pm$ $0.007) X-(0.071 \pm 0.022), Y$ the chromatographic response and $X$, the concentration in $\mu \mathrm{g} / \mathrm{mL}$ [30] [35]. The repeatability tests reported that relative standard deviations were less than $0.1 \%$ for the reference solutions and at $3.7 \%$ to a DXP in BALF sample for the chromatographic analysis and $2.7 \%$ for the whole procedure [36]. The overall recovery of DXP from BALF samples for concentrations 2,10 and $40 \mu \mathrm{g} / \mathrm{mL}$ was $84.3 \% \pm 1.6 \%$. Consistent recovery values at low, medium and high concentrations indicate the extraction process is acceptable across this range. The high recoveries observed indicate analyte stability under the extraction conditions applied and good extraction. The limits of detection and quantification were, respectively, 0.03 and $0.1 \mu \mathrm{g} / \mathrm{mL}$ [37].

\subsection{Application of Assay}

An example of chromatograms obtained from the extract of a DXP and IS (internal standard) in BALF samples from standard solutions and rats treated with DXP powder is given in Figure 2. DXP contents in BALF from rats treated, ranged from 31.5 to $0.1 \mu \mathrm{g} / \mathrm{mL}$ corresponding to DXP levels from $30 \mathrm{~min}$ to $24 \mathrm{~h}$ after lung administration. The results of DXP obtained in BALF were converted to epithelial lining fluid (ELF) concentrations according to the theoretical volume of ELF reported in the literature $(30 \mu \mathrm{L} / \mathrm{kg})$ and to the volume of PBS used for bronchoalveolar lavage $(1 \mathrm{~mL})$. Thus, for a rat of $300 \mathrm{~g}$, the dilution factor determined by calculation was 333 (Table 2) [38] [39]. All the observed concentrations of DXP in BALF and ELF lie within the ranges predicted by the PK model for the dosing regimen. This suggests that the assay is performing well and that the current HPLC method can be used successfully for the measurement of DXP levels in BALF samples Results indicate a greater degree of sensitivity is required to adequately detect DXP levels $18 \mathrm{~h}$ after administration in lung where the dose is low that the LOQ. Further work would include using a tandem mass spectrometer for greater selectivity and potentially increased detection sensitivity [40]. 


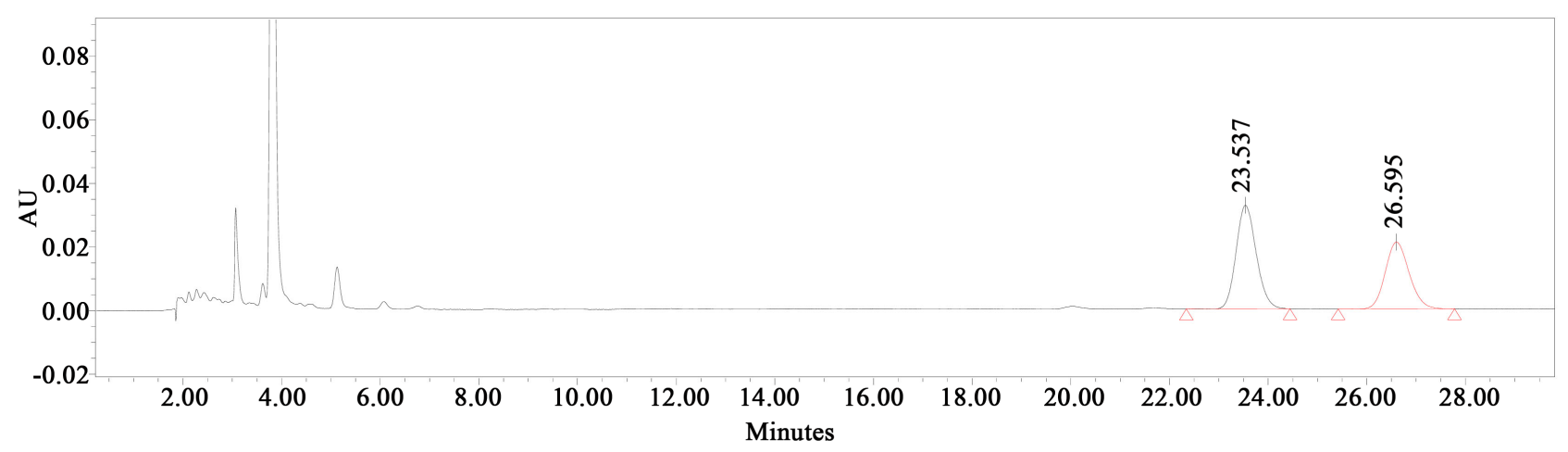

(a)

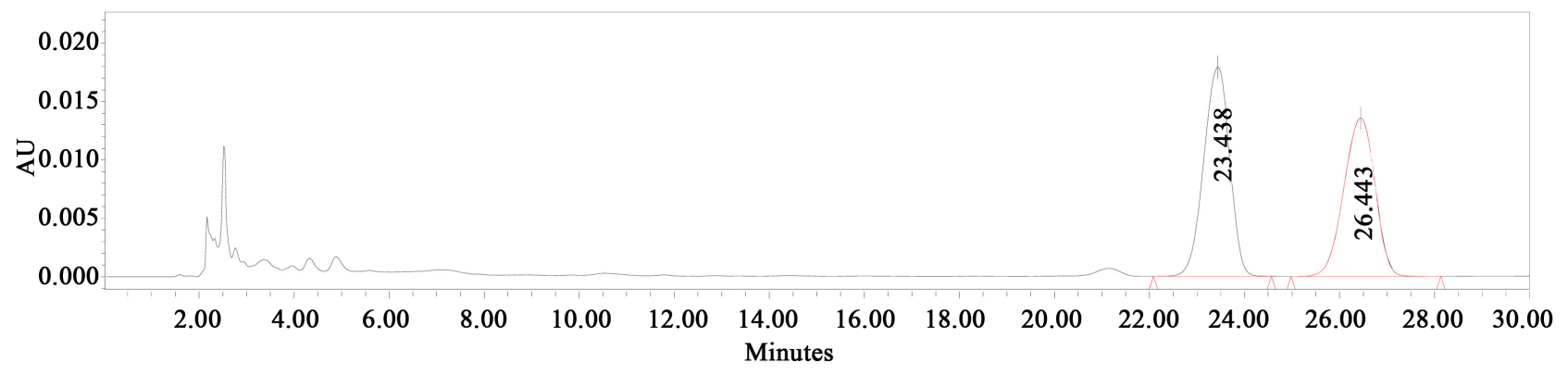

(b)

Figure 2. Chromatograms obtained from the extract of a DXP and IS in BALF samples from standard solutions (a) and rats treated sample (b).

Table 2. DXP contents in rats treated BALF and ELF after intratracheal insufflation of $3 \mathrm{mg}$ of DXP micro particles $(\mathrm{DXP}$ dose $=$ $150 \mu \mathrm{g}), \mathrm{n}=3$.

\begin{tabular}{ccccccccc}
\hline Temps $(\mathrm{h})$ & 0.5 & 1 & 2 & 3 & 4 & 6 & 18 & 24 \\
\hline BALF $(\mu \mathrm{g} / \mathrm{ml})$ & $31.5 \pm 4.4$ & $26.7 \pm 5.2$ & $20.4 \pm 1.9$ & $15.7 \pm 1.5$ & $5.1 \pm 2.1$ & $0.6 \pm 1.0$ & $0.1 \pm 0.0$ & $0.1 \pm 0.0$ \\
ELF $(\mu \mathrm{g} / \mathrm{ml})$ & $10,510.3 \pm 1471.7$ & $8894.4 \pm 1737.9$ & $6798.5 \pm 638.3$ & $5233.1 \pm 506.3$ & $1689.3 \pm 705.5$ & $204.2 \pm 333.6$ & $16.7 \pm 3.3$ & $12.5 \pm 1.7$ \\
\hline
\end{tabular}

\section{Conclusion}

A simple and sensitive HPLC method after chloroform-methanol extraction has been successfully developed for the quantification of DXP in BALF. The validated method has been shown to be accurate and precise with a RE and CV $\leq$ $15 \%$ at all tested concentrations. The validated method has been shown to be accurate and precise with an $\mathrm{RE}$ and $\mathrm{CV} \leq 15 \%$ at all tested concentrations. Requiring only a $100 \mu \mathrm{L}$ BALF sample, the method is well suited for application to inhaled drugs. The developed DXP method has been successfully applied to BALF samples collected from rats treated with a candidate innovating large porous particle and is being used to support an on-going PK study of inhaled DXP dry powder.

\section{Acknowledgements}

A. N'Guessan fellowship is supported by University Félix Houphouet-Boigny, Côte d'Ivoire, University Paris-Sud, Châtenay-Malabry and Institut Galien Paris-Sud CNRS UMR 8612. Authors would like to thank V. Domergue-Dupont, L. 
Aragão-Santiago, C. Ruge and D.D. Pham for support with animal experiments. Institut Galien Paris-Sud is a member of the Laboratory of Excellence LERMIT supported by a grant from ANR (ANR-10-LABX-33).

\section{Conflicts of Interest}

The authors declare no conflicts of interest regarding the publication of this paper.

\section{References}

[1] Barnes, P.J. (1995) Inhaled Glucocorticoids for Asthma. The New England Journal of Medicine, 332, 868-875. https://doi.org/10.1056/NEJM199503303321307

[2] Löfdahl, C.G., Mellstrand, T. and Svedmyr, N. (1983) Glucocorticoids and Asthma. Studies of Resistance and Systemic Effects of Glucocorticoids. European Journal of Respiratory Diseases. Supplement, 136, 69-79.

[3] Kaiser, H., Parasuraman, B., Boggs, R., Miller, C.J., Leidy, N.K. and O’Dowd, L. (2008) Onset of Effect of Budesonide and Formoterol Administered via One Pressurized Metered-Dose Inhaler in Patients with Asthma Previously Treated with Inhaled Corticosteroids. Annals of Allergy, Asthma \& Immunology, 101, 295-303. https://doi.org/10.1016/S1081-1206(10)60495-4

[4] Dolen, W.K. (1998) Inhaled Glucocorticoids in Asthma: Mechanisms and Clinical Actions. Annals of Allergy, Asthma \& Immunology, 81, 186. https://doi.org/10.1016/S1081-1206(10)62809-8

[5] Johnson, M. (1996) Pharmacodynamics and Pharmacokinetics of Inhaled Glucocorticoids. Journal of Allergy and Clinical Immunology, 97, 169-176. https://doi.org/10.1016/S0091-6749(96)80217-X

[6] Ben-Jebria, A., Chen, D., Eskew, M.L., Vanbever, R., Langer, R. and Edwards, D.A. (1999) Large Porous Particles for Sustained Protection from Carbachol-Induced Bronchoconstriction in Guinea Pigs. Pharmaceutical Research, 16, 555-561. https://doi.org/10.1023/A:1018879331061

[7] Edwards, D.A., Ben-Jebria, A. and Langer, R. (1998) Recent Advances in Pulmonary Drug Delivery Using Large, Porous Inhaled Particles. Journal of Applied Physiology, 85, 379-385. https://doi.org/10.1152/jappl.1998.85.2.379

[8] Heiati, H., Tawashi, R. and Phillips, N.C. (1998) Solid Lipid Nanoparticles as Drug Carriers: II. Plasma Stability and Biodistribution of Solid Lipid Nanoparticles Containing the Lipophilic Prodrug 3'-azido-3'-deoxythymidine Palmitate in Mice. International Journal of Pharmaceutics, 174, 71-80.

[9] Allen, D.B., Bielory, L., Derendorf, H., Dluhy, R., Colice, G.L. and Szefler, S.J. (2003) Inhaled Corticosteroids: Past Lessons and Future Issues. Journal of Allergy and Clinical Immunology, 112, S1-S40. https://doi.org/10.1016/S0091-6749(03)01859-1

[10] Wijagkanalan, W., Higuchi, Y., Kawakami, S., Teshima, M., Sasaki, H. and Hashida, M. (2008) Enhanced Anti-Inflammation of Inhaled Dexamethasone Palmitate Using Mannosylated Liposomes in an Endotoxin-Induced Lung Inflammation Model. Molecular Pharmacology, 74, 1183-1192. https://doi.org/10.1124/mol.108.050153

[11] Alhareth, K., Vauthier, C., Gueutin, C., Ponchel, G. and Moussa, F. (2012) HPLC Quantification of Doxorubicin in Plasma and Tissues of Rats Treated with Doxorubicin Loaded Poly(alkylcyanoacrylate) Nanoparticles. Journal of Chromatography $B$, 887-888, 128-132. https://doi.org/10.1016/j.jchromb.2012.01.025 
[12] Gómez-Gaete, C., Tsapis, N., Silva, L., Bourgaux, C., Besnard, M., Bochot, A. and Fattal, E. (2008) Supramolecular Organization and Release Properties of Phospholipid-Hyaluronan Microparticles Encapsulating Dexamethasone. European Journal of Pharmaceutics and Biopharmaceutics, 70, 116-126. https://doi.org/10.1016/j.ejpb.2008.04.013

[13] Gracia, A., Loureiro, M.L. and Nayga, R.M. (2011) Valuing an EU Animal Welfare Label Using Experimental Auctions. Agricultural Economics, 42, 669-677. https://doi.org/10.1111/j.1574-0862.2011.00543.x

[14] Knight, A. (2007) Systematic Reviews of Animal Experiments Demonstrate Poor Human Clinical and Toxicological Utility, AATEX 14, Special Issue, 125-130.

[15] Green, C.J., Knight, J., Precious, S. and Simpkin, S. (1981) Ketamine Alone and Combined with Diazepam or Xylazine in Laboratory Animals: A 10 Year Experience. Laboratory Animals, 15, 163-170. https://doi.org/10.1258/002367781780959107

[16] Wijagkanalan, W., Kawakami, S., Higuchi, Y., Yamashita, F. and Hashida, M. (2011) Intratracheally Instilled Mannosylated Cationic Liposome/NF $\kappa \mathrm{B}$ Decoy Complexes for Effective Prevention of LPS-Induced Lung Inflammation. Journal of Controlled Release, 149, 42-50. https://doi.org/10.1016/j.jconrel.2009.12.016

[17] Kang, Y.P., Lee, W.J., Hong, J.Y., Lee, S.B., Park, J.H., Kim, D., Park, S., Park, C.S., Park, S.W. and Kwon, S.W. (2014) Novel Approach for Analysis of Bronchoalveolar Lavage Fluid (BALF) Using HPLC-QTOF-MS-Based Lipidomics: Lipid Levels in Asthmatics and Corticosteroid-Treated Asthmatic Patients. Journal of Proteome Research, 13, 3919-3929. https://doi.org/10.1021/pr5002059

[18] Ohnishi, H.K.T., Mayeno, A., Okada, S., Sur, S., Broide, D.H. and Gleich, G.J. (1996) Lidocaine in Bronchoalveolar Lavage Fluid (BALF) Is an Inhibitor of Eosinophil-Active Cytokines. Clinical \& Experimental Immunology, 104, 325. https://doi.org/10.1046/j.1365-2249.1996.32737.x

[19] Li, Z.Q., Rong, X.Y., Liu, Y.J., Ni, C., Tian, X.S., Mo, N., Chui, D.H. and Guo, X.Y. (2013) Activation of the Canonical Nuclear Factor- $\kappa$ B Pathway Is Involved in Isoflurane-Induced Hippocampal Interleukin- $\beta$ Elevation and the Resultant Cognitive Deficits in Aged Rats. Biochemical and Biophysical Research Communications, 438, 628-634. https://doi.org/10.1016/j.bbrc.2013.08.003

[20] Timbrell, V. and Rendall, R.E.G. (1972) Preparation of the UICC Standard Reference Samples of Asbestos. Powder Technology, 5, 279-287. https://doi.org/10.1016/0032-5910(72)80032-9

[21] Kirchherr, H. and Kühn-Velten, W.N. (2006) Quantitative Determination of Forty-Eight Antidepressants and Antipsychotics in Human Serum by HPLC Tandem Mass Spectrometry: A Multi-Level, Single-Sample Approach. Journal of Chromatography B, 843, 100-113. https://doi.org/10.1016/j.jchromb.2006.05.031

[22] Lewis, T., Nichols, P.D. and McMeekin, T.A. (2000) Evaluation of Extraction Methods for Recovery of Fatty Acids from Lipid-Producing Microheterotrophs. Journal of Microbiological Methods, 43, 107-116. https://doi.org/10.1016/S0167-7012(00)00217-7

[23] Lane, S., Boughtflower, B., Mutton, I., Paterson, C., Farrant, D., Taylor, N., Blaxill, Z., Carmody, C. and Borman, P. (2005) Toward Single-Calibrant Quantification in HPLC. A Comparison of Three Detection Strategies: Evaporative Light Scattering, Chemilumines Cent Nitrogen, and Proton NMR. Analytical Chemistry, 77, 4354-4365. https://doi.org/10.1021/ac0502571

[24] Farin, D., Piva, G.A., Gozlan, I. and Kitzes-Cohen, R. (1998) A Modified HPLC 
Method for the Determination of Vancomycin in Plasma and Tissues and Comparison to FPIA (TDX). Journal of Pharmaceutical and Biomedical Analysis, 18, 367-372. https://doi.org/10.1016/S0731-7085(98)00095-8

[25] Kazakevich, Y.V. and Lobrutto, R. (2007) HPLC for Pharmaceutical Scientists. John Wiley \& Sons, Hoboken. https://doi.org/10.1002/0470087951

[26] Branch, S.K. (2005) Guidelines from the International Conference on Harmonisation (ICH). Journal of Pharmaceutical and Biomedical Analysis, 38, 798-805. https://doi.org/10.1016/j.jpba.2005.02.037

[27] Bidigare, R.R., Van Heukelem, L. and Trees, C.C. (2002) HPLC Phytoplankton Pigments: Sampling, Laboratory Methods, and Quality Assurance Procedures. In: Mueller, J.L. and Gargion, G., Eds., Ocean Optics Protocols for Satellite Ocean Color Sensor Validation, Revision 2, NASA Technical Memo, 258-268.

[28] Araujo, P. (2009) Key Aspects of Analytical Method Validation and Linearity Evaluation. Journal of Chromatography B, 877, 2224-2234. https://doi.org/10.1016/j.jchromb.2008.09.030

[29] Hubbs, A., Porter, D.W., Mercer, R., Castranova, V., Sargent, L. and Sriram, K. (2013) Chapter 43-Nanoparticulates. In: Haschek, W.M., Rousseaux, C.G. and Wallig, M.A., Eds., Handbook of Toxicologic Pathology, Third Edition, Academic Press, Boston, 1373-1419. https://doi.org/10.1016/B978-0-12-415759-0.00043-1

[30] Olson, C.L. (1976) On Choosing a Test Statistic in Multivariate Analysis of Variance. Psychological Bulletin, 83, 579. https://doi.org/10.1037//0033-2909.83.4.579

[31] Wang, Z., Kim, S., Quinney, S.K., Zhou, J. and Li, L. (2010) Non-Compartment Model to Compartment Model Pharmacokinetics Transformation Meta-Analysis: A Multivariate Nonlinear Mixed Model. BMC Systems Biology, 4, Article No. S8. https://doi.org/10.1186/1752-0509-4-S1-S8

[32] Beck-Broichsitter, M., Gauss, J., Packhaeuser, C.B., Lahnstein, K., Schmehl, T., Seeger, W., Kissel, T. and Gessler, T. (2009) Pulmonary Drug Delivery with Aerosolizable Nanoparticles in an Ex Vivo Lung Model. International Journal of Pharmaceutics, 367, 169-178. https://doi.org/10.1016/j.ijpharm.2008.09.017

[33] Sarkar, M., Khandavilli, S. and Panchagnula, R. (2006) Development and Validation of RP-HPLC and Ultraviolet Spectrophotometric Methods of Analysis for the Quantitative Estimation of Antiretroviral Drugs in Pharmaceutical Dosage Forms. Journal of Chromatography B, 830, 349-354. https://doi.org/10.1016/j.jchromb.2005.11.014

[34] Chan, C.C., Lee, Y.C., Lam, H. and Zhang, X.M. (2004) Analytical Method Validation and Instrument Performance Verification. John Wiley \& Sons, Hoboken. https://doi.org/10.1002/0471463728

[35] Van Midwoud, P.M., Rieux, L., Bischoff, R., Verpoorte, E. and Niederländer, H.A. (2007) Improvement of Recovery and Repeatability in Liquid Chromatography-Mass Spectrometry Analysis of Peptides. Journal of Proteome Research, 6, 781-791. https://doi.org/10.1021/pr0604099

[36] Amin, C.N., Bony, N.F., Gbassi, G.K. and Aké, M. (2014) Research and Determination of Tartrazine in Artisanal Yoghurts Commercialized in Abidjan (Côte d'Ivoire). International Journal of Nutrition and Food Sciences, 3, 119-122. https://doi.org/10.11648/j.ijnfs.20140302.25

[37] Ake, M., N'cho, C., Bony, F., Gbassi, G. and Atindehou, E. (2009) Evaluation of Vitamin B1 Status of Alcoholic Subjects in Abidjan (Côte d'Ivoire). International Journal of Biological and Chemical Sciences, 3, 1212-1218. https://doi.org/10.4314/ijbcs.v3i6.53135 
[38] Reynolds, S.D., Pinkerton, K.E. and Mariassy, A.T. (2015) Chapter 6-Epithelial Cells of Trachea and Bronchi. In: Parent, R.A., Ed., Comparative Biology of the Normal Lung, Second Edition, Academic Press, San Diego, 61-81. https://doi.org/10.1016/B978-0-12-404577-4.00006-0

[39] Eisenberg, E.J., Bidgood, A. and Cundy, K.C. (1997) Penetration of GS4071, a Novel Influenza Neuraminidase Inhibitor, into Rat Bronchoalveolar Lining Fluid Following Oral Administration of the Prodrug GS4104. Antimicrobial Agents and Chemotherapy, 41, 1949-1952. https://doi.org/10.1128/AAC.41.9.1949

[40] Nelson, R.E., Grebe, S.K., O’Kane, D.J. and Singh, R.J. (2004) Liquid Chromatography-Tandem Mass Spectrometry Assay for Simultaneous Measurement of Estradiol and Estrone in Human Plasma. Clinical Chemistry, 50, 373-384.

https://doi.org/10.1373/clinchem.2003.025478 